\title{
Differences between preterm infants receiving a dose for lung maturation and those receiving an additional rescue dose of corticosteroids
}

Abstract: It is unknown if there is a difference between preterm infants with a history of receiving pulmonary corticosteroid maturation or using an additional rescue dose of corticosteroid. This paper aims to determine the difference between infants with pulmonary maturation and infants who received a rescue dose of corticosteroid. We performed an epidemiological, observational, and cross-sectional study. We analyzed time of stay, the requirement of mechanical ventilation, the use of surfactant, and neurological complications in newborns hospitalized in Neonatology of the Isidro Ayora Gyneco-Obstetric Hospital, 2019. We analyzed 204 preterm infants of 28-37 weeks who received a total lung maturation dose versus an added rescue dose. We analyzed the information with the statistical program SPSS $\vee 22.0$. With rescue dose the stay time was $28.4 \pm 21.6$ days ( $p$ $<0.05)$, days of invasive mechanical ventilation $3 \pm 5.7$ days $(p<0.05)$; Surfactant use $33.3 \%(p>0.05)$. We found neurological complications in $6.9 \%$ of patients ( $p>0.05$ ). In group 2 with not rescue dose use, the stay time was $21.5 \pm 16.6$ days $(p<0.05)$, days of invasive mechanical ventilation $1.8 \pm 4.1$ days $(p<0.05)$. Surfactant use was $24.5 \%(p>0.05)$, and neurological complications $2 \%$ ( $>>0.05$ ). Preterm males weighing $<1000 \mathrm{~g}$ from 30 to 32 weeks, who used rescue doses of corticosteroids, showed an increase in intraventricular hemorrhage (13.7\%), seizures (6.9\%), and leukomalacia (13.7\%), associated with the fact that in the group with rescue dose they are younger and had lower weight.

Key words: Preterm birth; Respiratory Distress Syndrome, Pulmonary surfactants; Obstetric Labor, Preterm; prenatal exposure to corticosteroids.

\section{Introduction}

A single cycle of prenatal corticosteroids administered to mothers with early preterm birth improves survival, reduces respiratory distress syndrome, necrotizing enterocolitis, and intraventricular hemorrhage. It was not associated with any significant adverse effects for the mother or the unborn child in the short term ${ }^{1}$.

Prenatal corticosteroid therapy recommends all pregnancies with threatened preterm birth before 34 weeks of gestation, where the newborn's ongoing care is anticipated. Although there are limited data from randomized studies in infants with $<25$ weeks gestation, observational studies suggest that prenatal corticosteroids and other active treatment practices diminish pregnancy mortality to 22 weeks ${ }^{2}$. In pregnancies between 34 and 36 weeks of gestation, prenatal corticosteroids also reduce the risk of short-term respiratory morbidity but not mortality, and there is an increased risk of neonatal hypoglycemia ${ }^{3}$.

Given the potential for long-term side effects, it does not recommend corticosteroids for women in spontaneous preterm labor after 34 weeks. When administered before elective cesarean section, up to 39 weeks, reduce the risk of admission to the Neonatal Intensive Care Unit $(\mathrm{NICU})^{4}$, although follow-up data on term newborns exposed to prenatal corticosteroids lack $^{5}$.

The optimal interval between treatment and delivery is more than 24 hours and less than seven days after the start of corticosteroid treatment; beyond 14 days, the optimal interval between treatment and delivery is more than 24 hours and less than seven days after the start of corticosteroid treatment; beyond 14 days, the benefits decrease. The beneficial effects of the first dose of prenatal corticosteroids begin in a few hours, advanced dilation should not be a reason to refrain from therapy, and the same can happen with magnesium sulfate $(\mathrm{MgSO} 4)^{6}$. Corticosteroids should be repeated one to two weeks after the first course for women with the threat of preterm delivery. A repeated course reduces the risk of respiratory assistance. However, fetal growth decreases and repeated doses do not reduce mortality?

It observed no effect on neurosensory disability at follow-up, but data on possible longer-term adverse effects are lacking. The WHO recommends that a single corticosteroid cycle be used if preterm delivery does not occur within seven days after the initial course, and there is a high risk of preterm delivery within the next seven days. Repeated courses administered after 32 weeks of gestation do not improve the results ${ }^{8}$.

Indeed corticosteroids are medications with several side effects, such as impaired fetal and placental growth, apoptosis in the brain, and increased infection, but when properly managed, they are safe. The use of corticosteroids should be reduced by an adequate assessment of the risk of preterm delivery and avoiding unnecessary early elective cesarean section, which is the obstetrician's decision to terminate the pregnancy in a woman with a history of previous cesarean section. In some cases, when an early cesarean section is needed, the establishment of fetal lung maturity may be better than administering corticosteroids to all women. There is little evidence that cesarean delivery of preterm newborns instead of allowing vaginal delivery improves outcomes ${ }^{9}$. However, the recommendations of the European consensus guidelines for the prevention of hyaline membrane disease in preterm infants are summarized below ${ }^{10}$ : Mothers with a high risk of preterm birth $<28$-30 weeks gestation should transfer to perinatal centers with experience in the treatment of respiratory distress syndrome. A single cycle of prenatal corticosteroids should offer all women at risk of preterm birth when pregnancy is considered potentially viable until 34 weeks of gestation, ideally at least 24 hours before birth. A single cycle of corticos-

${ }^{1}$ Universidad San Francisco de Quito USFQ, Colegio Ciencias de la Salud, Quito, Ecuador.

${ }^{2}$ Universidad Central del Ecuador, Facultad de Ciencias Médicas, Unidad de Medicina Traslacional, Quito, Ecuador. 
teroids might be administered in the threat of preterm delivery before 32 weeks of gestation at least 1 to 2 weeks before. Magnesium sulfate should be administered to women in imminent labor before 32 weeks of gestation ${ }^{11}$.

In women with preterm birth symptoms, cervical length and fibronectin measures should consider avoiding unnecessary tocolytic medications and prenatal corticosteroids. Shortterm use of tocolytic drugs should be considered in early pregnancies to complete a corticosteroid cycle and transfer the uterus to a specialized perinatal center ${ }^{12}$

There are differences between European and national clinical practice guidelines for newborn care with respiratory distress. They recommend administering prenatal corticosteroids, in risky pregnancies, between 26 and 34 weeks, for two days and, it is not advisable to use repeated doses if the birth has not occurred after one week of the last dose since It has not shown additional benefits. The medications recommended in these guidelines are Betamethasone $e^{12,13}$. Despite the available evidence on the use of pulmonary maturation with corticosteroids in the threat of preterm birth, there is a possibility of using the rescue dose if the birth has not occurred after seven days of the last dose.

It observed a $17 \%$ reduction in respiratory distress and $16 \%$ in severe complications associated with prematurity in infants with corticosteroid rescue doses. Besides, the use of rescue dose is associated with non-significant reductions in the newborn's weight and size, which disappear at discharge and have no implications in early childhood ${ }^{14}$. McKinlay et $a l^{2}$ studied the results for one or more repeated doses of corticosteroids in newborns and pregnant women, demonstrating that corticosteroids decrease the incidence of neonatal death, respiratory distress syndromes, intraventricular hemorrhage, necrotizing enterocolitis, and early sepsis. Prenatal corticosteroid therapy increases the effectiveness of postnatal surfactant therapy. Corticosteroids can induce the maturation of fetal organs and improve the transition to life after childbirth.

In another systematic review, Hutchinson and Hodgden ${ }^{15}$ showed that women with preterm labor who received a cycle of corticosteroids and are still at risk of preterm delivery after seven days might benefit from a rescue dose. Studies discovered neonatal outcomes immediately after childbirth and no long-term risks in childhood by comparing growth, cardiovascular and endocrine functions. It also considered that maternal risks are not different between groups. Therefore, it considered additional corticosteroid therapy.

Indeed, preterm birth is the leading cause of death in children under five years of age worldwide; the rates of preterm infants' survival increase in high-income countries, neonates still die due to lack of attention or necessary supplies in middle and low-income countries. On the other hand, preterm birth remains a critical problem in infant mortality; it used antenatal corticosteroids to improve maternal and neonatal care quality. Despite this, inequality in survival rates is very different; in low-income countries, 32-week-old preterm newborns die due to lack of feasible and cost-effective care, while in high-income countries, almost all preterm neonates survive ${ }^{16}$.

It is possible to say that after the administration of prenatal corticosteroids between weeks 24 and 34, the structural and biochemical changes that the pneumocytes both I and II undergo; fetal lung maturity accelerate by increasing the production of natural surfactant; These changes, in turn, improve lung mechanics, which results in a decrease in respiratory distress, use of exogenous corticosteroids.

Knowing that the maximum benefit is obtained after the first 24 hours post-administration until seven days, years ago, the administration of repeated treatments was used as a daily practice, a practice that has become deprecated due to the adverse effects that the affected products presented both in its growth as fetal development ${ }^{14}$.

Prenatal corticosteroid administration is used to prevent respiratory distress syndrome in fetuses less than 34 weeks gestation in newborns who are still preterm newborns until birth and receive a rescue dose of corticosteroids. The purpose is to determine if there is a difference in the length of stay, the requirement for mechanical ventilation, the use of surfactant, and neurological complications ${ }^{17}$ to establish a new pharmacological regimen.

This new approach to prenatal therapy in patients with risk factors for preterm birth may increase infant survival with light birth weight ${ }^{18,19}$. The aim is to contribute to the neonatal population to improve birth conditions and avoid neonatal complications that affect the individual, family, and society ${ }^{20}$.

This work aims to determine the difference between infants with pulmonary maturation and those who received a rescue dose of corticosteroid concerning their time of stay, the requirement of mechanical ventilation, use of surfactant, and neurological complications in hospitalized newborns in the Neonatology Service of the Isidro Ayora Gyneco-Obstetric Hospital in 2019.

\section{Methods}

\section{Study design}

Epidemiological, observational, and cross-sectional study.

\section{Context}

Gyneco-Obstetric Hospital Isidro Ayora (HGOIA), in Quito, Ecuador. The analyzed period was from 14 November, 2019, to 29 January, 2020.

\section{Sample size}

204 newborns.

\section{Participants}

The population under study was from 28 to 37 weeks of gestational age, divided into two groups; one: received the total dose of corticosteroid lung maturation, and group two: complete lung maturation plus rescue dose.

\section{Inclusion criteria}

Preterm newborns with gestational age at birth from 28 to 37 of gestational age and history of prenatal corticosteroid use; that merited or not ventilatory support, use of surfactant, whether or not it presented neurological complications; of both sexes and any ethnic group. Group one received a total dose of fetal lung maturation with Betamethasone or Dexamethasone, while group two received a rescue dose before birth with Betamethasone or Dexamethasone.

\section{Exclusion criteria}

We excluded newborns referred to HGOIA with gestational age at birth over 37 and below 27 weeks of gestational age. 


\section{Elimination criteria}

There were newborns with congenital malformations incompatible with life who died during the study.

\section{Variables}

It developed a sheet with socio-demographic characteristics: sex, ethnicity, gestational age, classification of prematurity, birth weight. Regarding prenatal factors: week in which lung maturation was administered. Postnatal factors were the use of mechanical ventilation, surfactant use, number of surfactant doses, trans fontanel ultrasound, neurological complications, seizures, days of mechanical ventilation, and days of hospitalization. The diagnosis at admission and discharge: the degree of prematurity, birth weight, size for gestational age, respiratory pathology, neurological, infectious, metabolic, hematological, cardiac, and hemodynamic pathology.

\section{Sources, data, and measurements}

From the beginning of the study, it revised the medical records of preterm patients admitted to HGOIA to identify the necessary data for analysis and interpretation. It is essential to mention that gynecologists did not influence the therapeutic decision regarding preterm deliveries concerning prenatal corticosteroid therapy. We identified a pregnant mother who received pulmonary maturation and a rescue dose of corticosteroid before week 37 of gestation for the preterm newborn's follow-up during his hospital stay.

\section{Biases avoidance}

It collected information from complete medical records and by the same person consistently.

\section{Statistical methods}

The information obtained was stored in an Excel database and then analyzed with the SPSS ${ }^{\circledR}$ software version 22.0, licensed: 4-2E097 I. We used descriptive statistics: frequencies, percentages, average, standard deviation, and inferential: Chi-square test, a p-value less than 0.05 , which was accepted as statistical significance. We performed a multivariate analysis.

\section{Ethical criteria}

This research was approved by the Research Ethics Committee on Human Beings (CEISH) of the San Francisco University of Quito. It was dated 14 November of 2019, and coded with the number P2019-155TPG.

\section{Results}

Table 1 shows that, for both study groups, the variables that reached statistical significance using corticosteroid rescue doses were gestational age and the degree of prematurity $(p<0.05)$. There was no statistical significance between sex, ethnicity, or birth weight using rescue doses of corticosteroids ( $p>0.05$ ). See table 1. It included 204 preterm patients in this research, is divided into two patient groups, according to the

\begin{tabular}{|c|c|c|c|c|}
\hline \multirow{2}{*}{$\begin{array}{l}\text { Socio- } \\
\text { demographic } \\
\text { characteristics }\end{array}$} & \multicolumn{2}{|c|}{$\begin{array}{l}\text { Rescue dose lung maturation (n; } \\
\%)^{1}\end{array}$} & \multirow[t]{2}{*}{$X^{2}$} & \multirow[t]{2}{*}{$p<0,05$} \\
\hline & Yes & No & & \\
\hline \multicolumn{3}{|l|}{ Sex } & 0,729 & 0,393 \\
\hline Male & $57(55,9)$ & $63(61,8)$ & & \\
\hline Female & $45(44,1)$ & $39(38,2)$ & & \\
\hline \multicolumn{3}{|l|}{ Ethnicity } & 5,247 & 0,263 \\
\hline Afro-Ecuadorian & $3(2,9)$ & $1(1,0)$ & & \\
\hline Native American & $0(0,0)$ & $2(2,0)$ & & \\
\hline Mestizo & $97(95,1)$ & $94(92,2)$ & & \\
\hline Caucasian & $2(2,0)$ & $3(2,9)$ & & \\
\hline \multicolumn{3}{|c|}{ Gestational Age (weeks) } & 15,243 & $<0,001$ \\
\hline$<\mathbf{3 0}$ & $12(11,8)$ & $0(0,0)$ & & \\
\hline $30,1-33,6$ & $50(49,0)$ & $45(44,1)$ & & \\
\hline $34-36,6$ & $40(39,2)$ & $57(55,9)$ & & \\
\hline \multicolumn{3}{|c|}{ Prematurity classification } & 11,67 & 0,003 \\
\hline Very preterm & $32(31,4)$ & $12(11,8)$ & & \\
\hline Moderate & $28(27,5)$ & $34(33,3)$ & & \\
\hline Late & $42(41,2)$ & $56(54,9)$ & & \\
\hline \multicolumn{5}{|l|}{ Birth weight (g) } \\
\hline Mean \pm DE & $1571 \pm 362$ & $1833 \pm 431$ & 170,0 & 0,094 \\
\hline Min-MAX & $890-2340$ & $855-2835$ & & \\
\hline Total & $102(100,0)$ & $102(100,0)$ & & \\
\hline
\end{tabular}

Table 1. Distribution of socio-demographic characteristics according to the rescue dose of pulmonary maturation. Preterm newborns, Isidro Ayora Gyneco-Obstetric Hospital, 2019. 
use of a rescue dose of lung maturation, and it split each group of 102 patients.

Table 2 shows that there were significant differences between the time when lung maturation in both groups ( $p$ $<0.001$ ); it was administered later among patients who did not receive rescue dose (31.3 \pm 2.1 weeks), compared to the group in which rescue dose was administered ( $30.5 \pm 2.9$ weeks). There was also statistical significance between mechanical ventilation and hospitalization days in both study groups ( $p<0.05)$. There was no statistical significance between mechanical ventilation modality, surfactant use, surfactant dose number, trans fontanelar ultrasound, neurological complica- tions, seizures, or days of mechanical ventilation in both study groups ( $p>0.05)$.

Table 3 shows the time of admission; there was statistical significance for the association between the use of rescue doses of corticosteroids with the degree of prematurity and the newborn's size $(p<0.05)$. There was no statistical significance for the association between birth weights, the presence of respiratory, neurological, infectious, metabolic, hematological, or renal pathologies using rescue doses of corticosteroids ( $p>$ 0.05).

Table 4 shows that, at the time of discharge, there was a

\begin{tabular}{|c|c|c|c|c|}
\hline \multirow[t]{2}{*}{ Prenatal } & \multicolumn{2}{|c|}{$\begin{array}{l}\text { Rescue dose lung maturation } \\
\qquad(\mathrm{n} ; \%)^{1}\end{array}$} & \multirow[t]{2}{*}{$X^{2}$} & \multirow[t]{2}{*}{$p<0,05$} \\
\hline & Yes & No & & \\
\hline \multicolumn{5}{|c|}{ Week in which lung maturation was administered } \\
\hline Mean \pm SD & $30,5 \pm 2,9$ & $31,3 \pm 2,1$ & 50,94 & $<0,001$ \\
\hline Min-MAX & $25-35,4$ & $25-35$ & & \\
\hline \multicolumn{5}{|l|}{ Postnatal } \\
\hline \multicolumn{3}{|l|}{ Mechanic ventilation } & 4,738 & 0,094 \\
\hline No & $39(38,2)$ & $41(40,2)$ & & \\
\hline Non-invasive & $20(19,6)$ & $31(30,4)$ & & \\
\hline Invasive + non-invasive & $43(42,2)$ & $30(29,4)$ & & \\
\hline \multicolumn{3}{|l|}{ Use of pulmonary surfactant } & 1,932 & 0,165 \\
\hline Yes & $34(33,3)$ & $25(24,5)$ & & \\
\hline No & $68(66,7)$ & $77(75,5)$ & & \\
\hline \multicolumn{3}{|l|}{ Number of surfactant dose } & 5,152 & 0,076 \\
\hline A dose & $23(22,5)$ & $22(21,6)$ & & \\
\hline$>1$ dose & $11(10,8)$ & $3(2,9)$ & & \\
\hline Not use surfactant & $68(66,7)$ & $77(75,5)$ & & \\
\hline \multicolumn{3}{|l|}{ Ecografía transfontanelar } & 9,499 & 0,147 \\
\hline No & $29(28,4)$ & $32(31,4)$ & & \\
\hline Intraventricular hemorrhage & $14(13,7)$ & $11(10,8)$ & & \\
\hline Leukomalacia & $14(13,7)$ & $5(4,9)$ & & \\
\hline Choroid cyst & $7(6,9)$ & $4(3,9)$ & & \\
\hline Hydrocephalus & $0(0,0)$ & $3(2,9)$ & & \\
\hline Normal & $38(37,3)$ & $47(46,1)$ & & \\
\hline \multicolumn{3}{|l|}{ Neurological complications } & 2,906 & 0,085 \\
\hline Yes & $7(6,9)$ & $2(2,0)$ & & \\
\hline No & $95(93,1)$ & $100(98,0)$ & & \\
\hline \multicolumn{5}{|l|}{ Seizures } \\
\hline Yes & $7(6,9)$ & $2(2,0)$ & 2,906 & 0,085 \\
\hline No & $95(93,1)$ & $100(98,0)$ & & \\
\hline \multicolumn{3}{|c|}{ Days of Invasive Mechanical Ventilation } & 29,9 & 0,023 \\
\hline Mean \pm DE & $3 \pm 5,7$ & $1,8 \pm 4,1$ & & \\
\hline Min-MAX & $0-30$ & $0-26$ & & \\
\hline \multicolumn{3}{|c|}{ Days of Non-invasive Mechanical Ventilation } & 17,00 & 0,523 \\
\hline Mean \pm DE & $3,5 \pm 4,5$ & $2,5 \pm 3,6$ & & \\
\hline Min-MAX & $0-22$ & $0-17$ & & \\
\hline \multicolumn{3}{|l|}{ Hospitalization days } & 67,6 & 0,015 \\
\hline Mean $\pm \mathbf{D E}$ & $28,4 \pm 21,6$ & $21,5 \pm 16,6$ & & \\
\hline Min-MAX & 4-104 & 3-85 & & \\
\hline Total & $102(100,0)$ & $102(100,0)$ & & \\
\hline
\end{tabular}

Table 2. Distribution of prenatal and postnatal history according to the rescue dose of pulmonary maturation. Preterm newborns, Isidro Ayora Gyneco-Obstetric Hospital, 2019. 


\begin{tabular}{|c|c|c|c|c|}
\hline \multirow[t]{2}{*}{ Diagnosis at admission } & \multicolumn{2}{|c|}{$\begin{array}{l}\text { Rescue dose lung } \\
\text { maturation }(\mathrm{n} ; \%)^{1}\end{array}$} & \multirow[t]{2}{*}{$X^{2}$} & \multirow[t]{2}{*}{$p<0.05$} \\
\hline & Yes & No & & \\
\hline \multicolumn{3}{|l|}{ Recién nacido según prematuridad } & 9,522 & 0,023 \\
\hline RNpT (mp) & $14(13,7)$ & $3(2,9)$ & & \\
\hline RNpT (m) & $53(52,0)$ & $52(51,0)$ & & \\
\hline $\mathrm{RNpT}(\mathrm{t})$ & $35(34,3)$ & $47(46,1)$ & & \\
\hline \multicolumn{3}{|l|}{ Newborn according to prematurity } & 2,974 & 0,226 \\
\hline Adequate weight & $5(4,9)$ & $10(9,8)$ & & \\
\hline Low weight & $92(90,2)$ & $90(88,2)$ & & \\
\hline Very low weight & $5(4,9)$ & $2(2,0)$ & & \\
\hline \multicolumn{3}{|l|}{ Newborn according to size } & 9,202 & 0,002 \\
\hline Small for gestational age & $36(35,3)$ & $17(16,7)$ & & \\
\hline Suitable for gestational age & $66(64,7)$ & $85(83,3)$ & & \\
\hline \multicolumn{3}{|l|}{ Respiratory pathology } & 4,053 & 0,542 \\
\hline Respiratory distress syndrome & $54(52,9)$ & $58(56,9)$ & & \\
\hline Hyaline Membrane Disease & $23(22,5)$ & $14(13,7)$ & & \\
\hline Adaptive syndrome & $2(2,0)$ & $2(2,0)$ & & \\
\hline Transient tachypnea of the newborn & $5(4,9)$ & $4(3,9)$ & & \\
\hline Several & $0(0,0)$ & $1(1,0)$ & & \\
\hline \multicolumn{3}{|l|}{ Neurological pathology } & 4,223 & 0,238 \\
\hline Initial depression & $5(4,9)$ & $6(5,9)$ & & \\
\hline Prenatal asphyxia & $0(0,0)$ & $1(1,0)$ & & \\
\hline Malformations of the neural tube & $0(0,0)$ & $3(2,9)$ & & \\
\hline \multicolumn{3}{|l|}{ Infectious Pathology } & 5,552 & 0,475 \\
\hline RPM sepsis risk & $10(9,8)$ & $10(9,8)$ & & \\
\hline Risk of sepsis due to chorioamnionitis & $4(3,9)$ & $2(2,0)$ & & \\
\hline Risk of sepsis due to septic delivery & $4(3,9)$ & $1(1,0)$ & & \\
\hline $\begin{array}{l}\text { Risk of sepsis due to urinary tract infection } \\
\text { or bacterial vaginosis }\end{array}$ & $22(21,6)$ & $16(15,7)$ & & \\
\hline Perinatal exposed & $0(0,0)$ & $1(1,0)$ & & \\
\hline TORCH exposed & $3(2,9)$ & $2(2,0)$ & & \\
\hline \multicolumn{3}{|l|}{ Metabolic pathology } & 4,601 & 0,203 \\
\hline Hypoglycemia & $7(6,9)$ & $4(3,9)$ & & \\
\hline Asymmetric RCIU & $10(9,8)$ & $4(3,9)$ & & \\
\hline Symmetric RCIU & $3(2,9)$ & $6(5,9)$ & & \\
\hline \multicolumn{3}{|l|}{ Hematological pathology } & 5,021 & 0,285 \\
\hline Jaundice of prematurity & $0(0,0)$ & $2(2,0)$ & & \\
\hline Multifactorial jaundice & $2(2,0)$ & $0(0,0)$ & & \\
\hline ABO incompatibility & $3(2,9)$ & $3(2,9)$ & & \\
\hline Polycythemia & $3(2,9)$ & $1(1,0)$ & & \\
\hline \multicolumn{3}{|l|}{ Renal pathology } & & \\
\hline No & $102(100,0)$ & $102(100,0)$ & & \\
\hline Total & $102(100,0)$ & $102(100,0)$ & & \\
\hline
\end{tabular}

Source: Medical records, Isidro Ayora Gyneco-Obstetric Hospital

Prepared by: authors (2020).

RNpT (mp): very preterm newborn; RNpT (m): moderate preterm newborn; RNpT (t): late preterm newborn; RPM: the preterm rupture of membranes; RCIU: intrauterine growth retardation.

Table 3. According to rescue dose of pulmonary maturation in preterm infants, distribution of diagnosis at admission, Isidro Ayora Gyneco-Obstetric Hospital, 2019. 


\begin{tabular}{|c|c|c|c|c|}
\hline \multirow[t]{2}{*}{ Diagnosis at discharge } & \multicolumn{2}{|c|}{$\begin{array}{c}\text { Rescue dose lung } \\
\text { maturation }(n ; \%)^{1}\end{array}$} & \multirow[t]{2}{*}{$X^{2}$} & \multirow[t]{2}{*}{$p<0,05$} \\
\hline & Sí & No & & \\
\hline \multicolumn{3}{|l|}{ Newborn according to prematurity } & 6,862 & 0,032 \\
\hline RNpT (mp) & $12(11,8)$ & $3(2,9)$ & & \\
\hline $\operatorname{RNpT}(\mathrm{m})$ & $53(52,0)$ & $51(50,0)$ & & \\
\hline RNpT (t) & $37(36,3)$ & $48(47,1)$ & & \\
\hline \multicolumn{3}{|l|}{ Newborn according to prematurity } & 1,332 & 0,514 \\
\hline Adequate weight & $2(2,0)$ & $2(2,0)$ & & \\
\hline Low weight & $95(93,1)$ & $98(96,1)$ & & \\
\hline Very low weight & $5(4,9)$ & $2(2,0)$ & & \\
\hline \multicolumn{3}{|l|}{ Newborn according to size } & 14,87 & $<0,001$ \\
\hline Small for gestational age & $38(37,3)$ & $14(13,7)$ & & \\
\hline Suitable for gestational age & $64(62,7)$ & $88(86,3)$ & & \\
\hline \multicolumn{3}{|l|}{ Respiratory pathology } & 14,23 & 0,162 \\
\hline Respiratory distress syndrome & $18(17,6)$ & $26(25,5)$ & & \\
\hline Hyaline Membrane Disease & $39(38,2)$ & $30(29,4)$ & & \\
\hline Adaptive syndrome & $0(0,0)$ & $2(2,0)$ & & \\
\hline Taquipnea transitoria del recién nacido & $7(6,9)$ & $10(9,8)$ & & \\
\hline Displasia broncopulmonar & $2(2,0)$ & $0(0,0)$ & & \\
\hline Transient tachypnea of the newborn & $12(11,8)$ & $6(5,9)$ & & \\
\hline Several & $3(2,9)$ & $5(4,9)$ & & \\
\hline \multicolumn{3}{|l|}{ Neurological pathology } & 3,81 & 0,283 \\
\hline Initial depression & $5(4,9)$ & $9(8,8)$ & & \\
\hline Seizures & $5(4,9)$ & $1(1,0)$ & & \\
\hline Malformations of the neural tube & $2(2,0)$ & $2(2,0)$ & & \\
\hline \multicolumn{3}{|l|}{ Infectious Pathology } & 16,46 & 0,05 \\
\hline $\begin{array}{l}\text { Risk of sepsis due to preterm rupture of } \\
\text { ovular membranes }\end{array}$ & $5(4,9)$ & $5(4,9)$ & & \\
\hline Risk of sepsis due to chorioamnionitis & $0(0,0)$ & $2(2,0)$ & & \\
\hline Risk of sepsis due to septic delivery & $2(2,0)$ & $0(0,0)$ & & \\
\hline $\begin{array}{l}\text { Risk of sepsis due to urinary tract infection } \\
\text { or bacterial vaginosis }\end{array}$ & $7(6,9)$ & $4(3,9)$ & & \\
\hline Perinatal exposed & $0(0,0)$ & $1(1,0)$ & & \\
\hline TORCH exposed & $3(2,9)$ & $0(0,0)$ & & \\
\hline Septic shock & $8(7,8)$ & $2(2,0)$ & & \\
\hline Early sepsis & $33(32,4)$ & $27(26,5)$ & & \\
\hline Late sepsis & $3(2,9)$ & $2(2,0)$ & & \\
\hline \multicolumn{3}{|l|}{ Metabolic pathology } & 5,342 & 0,254 \\
\hline Hypoglycemia & $7(6,9)$ & $4(3,9)$ & & \\
\hline Asymmetric RCIU & $16(15,7)$ & $8(7,8)$ & & \\
\hline Symmetric RCIU & $7(6,9)$ & $6(5,9)$ & & \\
\hline \multicolumn{3}{|l|}{ Hematological pathology } & 5,77 & 0,450 \\
\hline Jaundice of prematurity & $17(16,4)$ & $14(13,7)$ & & \\
\hline Multifactorial jaundice & $34(33,3)$ & $24(23,5)$ & & \\
\hline ABO incompatibility & $10(9,8)$ & $10(9,8)$ & & \\
\hline Anemia & $12(11,8)$ & $12(11,8)$ & & \\
\hline Several & $0(0,0)$ & $2(2,0)$ & & \\
\hline \multicolumn{3}{|l|}{ Cardiac and hemodynamic pathology } & 6,159 & 0,188 \\
\hline Persistence of the ductus arteriosus & $2(2,0)$ & $7(6,9)$ & & \\
\hline Inter earphone communication & $2(2,0)$ & $1(1,0)$ & & \\
\hline Cardiogenic shock & $2(2,0)$ & $0(0,0)$ & & \\
\hline Patent Oval Trench & $0(0,0)$ & $1(1,0)$ & & \\
\hline Total & $102(100,0)$ & $102(100,0)$ & & \\
\hline
\end{tabular}

Table 4. According to the rescue dose of pulmonary maturation in preterm infants, the distribution of diagnosis at discharge is determined by Isidro Ayora Gyneco-Obstetric Hospital, 2019. 
statistically significant association between the degree of prematurity, the size of newborns, and the presence of infectious diseases, using rescue doses of corticosteroids $(p<0.05)$. There was no statistical significance between birth weights, respiratory, neurological, metabolic, hematological, cardiovascular, or renal pathologies, using rescue doses of corticosteroids at discharge $(p>0.05)$. See table 4.

Table 5 shows the model summary. We used for the multivariate analysis a binomial logistic regression model. The variables that obtained statistical significance were included in the bivariate analysis. A 50\% probability of success was obtained with this model, which is very low, and a Negelkerke statistic $=28.4 \%$. The goodness of fit test of Hosmer and Lemeshow obtained statistical significance $(p<0.05)$, thereby increasing the probability of prediction to $71.1 \%$. The only variable associated with corticosteroid rescue doses was the newborn size $(p<0.05)$.

\begin{tabular}{|c|c|c|c|c|c|c|}
\hline & B & $\begin{array}{c}\text { Standard } \\
\text { error }\end{array}$ & Wald & $\mathrm{gl}$ & Sig. & $\operatorname{Exp}(B)$ \\
\hline Small for gestational age & 1,181 & 0,411 & 8,241 & 1 & 0,004 & 0,307 \\
\hline
\end{tabular}

\section{Source: Medical records, Isidro Ayora Gyneco-Obstetric Hospital Prepared by: authors (2020).}

Table 5. Multivariate análisis.

\section{Discussion}

We analyzed the behavior of two groups of infants with prematurity. In the first group, we included those who had received rescue doses of corticosteroids. In the second group, newborns who had not received this rescue dose, applying a new dose of corticosteroids when birth did not occur after seven days of completing the pulmonary maturation scheme.

In both study groups, male sex predominated, which accounted for $55.9 \%$ of cases. This factor explains in male fetuses an increased risk of prematurity, low birth weight, probability of complications, and death. This variable explains fetal testosterone's action on the pituitary hypothalamus axis, with an adverse feedback action, which affects the secretion hormones that prolong pregnancy. It knows that fetal sex influences the risk of adverse outcomes in response to prenatal corticosteroid therapy. It states that the chromosomal differences in both sexes' placenta are essential in determining fetal responses to prenatal noxas and prematurity. Female preterm infants respond more effectively to prenatal betamethasone exposure than their male counterparts, with lower respiratory distress syndrome rates, by the action of female hormones.

On the other hand, gestational age was statistically significantly related to corticosteroid rescue doses (30.1-33.6 weeks: 49\%), so in the group of patients in the corticosteroid rescue dose was used, the most frequent gestational age was 30.1 to 33.6 weeks. This variable explains that lung immaturity in these neonates is higher due to the respiratory system's formation not completed. The few alveoli that exist do not produce pulmonary surfactant in sufficient quantity and quality. Therefore, the risk increases bronchopulmonary dysplasia and respiratory distress. Besides, since these are newborns in whom the risk was identified early, they were given lung maturation more than seven days before birth occurred.

On the other hand, the patients' degree of prematurity was also significantly associated with the rescue dose of cor- ticosteroids. In this group, late preterm patients (41.2\%) predominated, and, at the time of admission, there was a higher percentage than was classified as moderate preterm, with statistically significant differences $(p<0.05)$ indicating that it was administered early lung maturation. For this reason, the dose of corticosteroids was repeating, but it could also be patients with significant respiratory dysfunction or with a high risk of complications such as bronchopulmonary dysplasia. Also, it accepts that preterm infants' respiratory complications decrease as gestational age increases, and the survival benefits of using additional doses of corticosteroids after 33 weeks have been discussed. However, we reported that yes, It is beneficial due to adaptive syndrome in late preterm infants.

Another finding was that the birth weight was lower in infants who received rescue doses of corticosteroids [1571 \pm 362 $\mathrm{g}$ ], the minimum weight was $890 \mathrm{~g}$, and the maximum weight was 2340 g; however, not was statistically significant. The criteria for using the rescue dose of corticosteroids are based on their administration when labor has not occurred within seven 
of the respiratory system's immaturity and the surfactant deficit was higher than in other newborns. Sphingomyelin, another component of the surfactant, has a constant production throughout pregnancy, but other components such as lecithin and phosphatidylglycerol begin to occur after 25 weeks would explain its deficit in the very preterm.

The use of surfactants among infants with corticosteroid rescue doses was higher and the other newborns. However, without statistical significance ( $p>0.05)$, which shows that offering another dose of corticosteroids, Prenatal, did not have an important influence on preventing hyaline membrane disease, which is the consequence of lung immaturity the absence of pulmonary surfactant. This factor complements the lack of usefulness of the rescue dose of corticosteroids in preventing respiratory complications, which in these cases depends more on the degree of prematurity and lung immaturity than on the pulmonary maturation scheme offered. It was also more frequent in patients with corticosteroid rescue than additional doses of surfactant (10.8\%) compared to the group without corticosteroid rescue, indicating no improvement in respiratory distress in patients' first six hours surfactant administered.

On the other hand, when analyzing the trans fontanel ultrasound and corticosteroid rescue dose results, it was obtained that intraventricular hemorrhage (13.7\%), leukomalacia, and choroidal cysts were more frequent in neonates with a rescue dose of corticosteroids, although it was not statistically significant. The effect of corticosteroids on preterm infants' central nervous system is substantial, with intraventricular hemorrhage complications. Indeed, an increase in central venous pressure, which usually occurs during labor, and when respiratory complications occur, which increased with the use of corticosteroids, which is assigned an essential role in the appearance of periventricular leukomalacia, which is related to an increase in interleukin 6, which is due to a local inflammatory process, which can subsequently bleed.

Intraventricular hemorrhage of the neonate is associated with increased cerebral blood flow and blood pressure, which is complicated by the vascular alterations that accompany hypoxemia and metabolic acidosis of neonates with respiratory distress. The use of additional doses of corticosteroids can contribute to weakening the capillary wall.

Seizures among infants who had received the rescue dose of corticosteroids were also more frequent than in other newborns. The cause of these seizures is probably due to the higher frequency of intraventricular hemorrhage in preterm infants with rescue doses of corticosteroids. Numerous mechanisms make immature brains hyperexcitable. First, the neonatal period is a period of physiological synaptogenesis, and both the synapse and the density of the dendritic spine are at their peak. Secondly, glutamatergic neurons, the primary excitation mechanism of both the neonatal brain, are excessively abundant. Their receptors have subunits that allow relative hyperexcitability; with the up-regulation mechanism, the number of receptors increases, and with the down-regulation mechanism, the number of receivers decreases.

Third, gamma-amino-butyric acid (GABA), the primary inhibitory mechanism of the adult brain, can exert a paradoxical exciting action on the developing brain due to the preponderance of the sodium, potassium, and chloride cotransporter (NKCC1) and the Delayed expression of KCC2 chloride cotransporters, which leads to a high concentration of intracellular chloride and depolarization in response to GABAergic agents.

There was a significant difference in the patients' group with corticosteroid rescue doses [28.4 21.6$]$ and the others.
It could correspond to the higher frequency of days of mechanical ventilation, due to the pulmonary immaturity associated with the higher degree of prematurity in this group, with the neurological and infectious complications, which were in this study group, compared to infants who did not receive the rescue dose of corticosteroids. Other factors that could have influenced the more magnificent hospital stay of these patients are the lower birth weight and gestational age in this group than the other, which also predisposes to the appearance of multiple complications.

Also, within respiratory complications, upon admission: hyaline membrane disease was present in $22.5 \%$ of infants who received rescue doses of corticosteroids and in $13.7 \%$ of those who did not receive it without statistical significance ( $p>$ 0.05). Similarly, at the time of discharge from the NICU, no statistically significant intergroup differences were obtained, an essential effect of the rescue dose of corticosteroids on the prognosis, and the reduction of complications of infants who received it. Corticosteroids accelerate the morphological differentiation of epithelial cells in type II cells, increase the rate of phosphatidylcholine synthesis and cause the accumulation of messenger RNAs for B-surfactant proteins $(\mathrm{Mr}=7000)$ and $\mathrm{C}$ $(\mathrm{Mr}=5000)$. Induction of phospholipid surfactants and mRNA proteins occurs rapidly, reverses, and appears to be mediated by receptors.

However, no significant effect was found in reducing hyaline membrane disease in this work, probably due to this group's infants' great prematurity. The production of surfactants mediates not all the effects of prenatal corticosteroids in the prevention of respiratory distress. A rapid removal of fluid from the lung to allow efficient gas exchange at the alveolar surface is key to the fetus's transition to other uterus life. The signaling of cellular corticosteroid receptors influences the function of several proteins involved in the mediation of alveolar fluid clearance; they include a subunit of the epithelial sodium channel $(\mathrm{aENaC})$ and the $\mathrm{al}$ and bl subunits of the adenosine triphosphate-based basolateral pump (ATP), both expressed in the respiratory epithelium.

Therefore, at the time of admission, neurological pathology was more frequent among infants in whom the rescue dose of corticosteroids, but this difference was very discrete and did not obtain statistical significance. At the time of discharge, neurological complications did not have statistical significance among the study groups ( $p>0.05$ ), indicating that the rescue dose of corticosteroids did not interfere; Although there is evidence that links the use of corticosteroids with neurological disorders such as intra-parenchymal hemorrhage and neonatal seizures. These complications were more frequent in the group that received the rescue dose, but it was not statistically significant.

Besides, neonatal infections at the time of admission had no significant differences between the two study groups ( $p>0.05)$, although they were more frequent in the group that received the rescue dose, within these, the risk for urinary tract infection (21.6\%). However, at the time of discharge from neonatal ICU, there were essential differences between the two groups $(p<0.05)$, with a clear predominance in neonates who received the rescue dose, where early sepsis predominated $(32.4 \%)$ and septic shock (7.8\%). The immunosuppressive effect of corticosteroids predisposes to the appearance of infections at all levels.

The use of rescue doses of corticosteroids in the neonatal period is associated with a higher probability of developing prenatal infections, such as chorioamnionitis and endometritis. It also increases the risk of early neonatal sepsis due to its suppressive effect on cellular and humoral immunity and 
decreases the production of lymphocytes, interleukins, and tumor necrosis factors, through a decrease in the stability of messenger RNA.

There were no significant differences between the two study groups when admission or discharge concerning metabolic pathologies. At admission, intrauterine growth restriction affected $9.8 \%$ of infants on corticosteroid rescue doses. This percentage was $15.7 \%$ at discharge. It associates corticosteroids' action on fetal growth with reduced size and weight at birth and intrauterine growth restriction.

Nor was an essential relationship between hematological pathologies and the use of rescue doses of corticosteroids at the time of admission or discharge. The most frequent cases were multifactorial jaundice in the group of those who received rescue doses (33.3\%) but without statistical significance ( $p>0.05$ ). In this case, jaundice seems to correspond to the interaction of several factors related to enzymatic immaturity, the use of antibiotics, or neonatal sepsis.

Similarly, cardiovascular and hemodynamic conditions did not have a significant difference in both study groups; at discharge from the NICU, infants in whom the rescue dose was not used had a higher incidence of this type of complications, significantly the persistence of the ductus arteriosus, which is a malformation in which the use of rescue doses of prenatal corticosteroids is not involved.

In summary, the most critical findings were, in the group that received rescue doses, which included very preterm newborns, there was an increase in the number of days of mechanical ventilation and infectious complications, which at the same time was associated with an increase in hospitalization days.

\section{Limitations}

The sample was adequate but could be extended to another population group from other hospitals and provinces.

\section{Generalization}

It is possible to generalize this research following a multicenter and prospective design.

\section{Conclusions}

Preterm males weighing $<1000 \mathrm{~g}$ from 30 to 32 weeks, who used rescue doses of corticosteroids, showed an increase in intraventricular hemorrhage (13.7\%), seizures (6.9\%), and leukomalacia (13.7\%), associated with the fact that in the group with rescue dose they are younger and had lower weight.

\section{Acknowledgments}

Authors thanks Gonzalo Mantilla, Luis Eguiguren, Hugo Burgos, Ana María Merchán-Tamariz, Alonso Herrera, and Humberto Navas López, for their support to this work.

\section{Funding}

Authors self-funding.

\section{Conflict of interest}

The authors report NO conflict of interest.

\section{Ethical approval}

This research was approved by the Research Ethics Committee on Human Beings (CEISH) of the San Francisco University of Quito. It was dated 14 November of 2019, and coded with the number P2019-155TPG.

\section{Informed consent}

It obtained Informed consent from all individual participants included in the study.

\section{Consent for publication}

The institutions cited in this document gave their consent to use this information.

\section{Bibliographic references}

1. Roberts D, Brown J, Medley N, Dalziel SR. Antenatal corticosteroids for accelerating fetal lung maturation for women at risk of preterm birth. Cochrane Database Syst Rev. 201721 March;3(3):89-104. DOl: 10.1002/14651858.CD004454.pub3.

2. McKinlay CJD, Crowther CA, Middleton P, Harding JE. Repeat antenatal Corticosteroids for women at risk of preterm birth: A Cochrane Systematic Review. Am J Obstet Gynecol. 2012 Mar;206(3):187-194. DOI: 10.1016/j.ajog.2011.07.042.

3. Ehret DEY, Edwards EM, Greenberg LT, Bernstein IM, Buzas JS, Soll RF, et al. Association of Antenatal Steroid Exposure With Survival Among Infants Receiving Postnatal Life Support at 22 to 25 Weeks' Gestation. JAMA Netw Open. 2018 Oct 5;1(6):e183235. DOI: 10.1001/jamanetworkopen.2018.3235.

4. Sotiriadis A, Makrydimas G, Papatheodorou S, Ioannidis JPA, Mcgoldrick E. Corticosteroids for preventing neonatal respiratory morbidity after elective cesarean section at term. Cochrane Database Syst Rev. 20183 August;8(8): CD006614. DOI: 10.1002/14651858.CD006614.pub3.

5. Kamath-Rayne BD, Rozance PJ, Goldenberg RL, Jobe AH. Antenatal corticosteroids beyond 34 weeks gestation: What do we do now? Am J Obstet Gynecol. 20161 October;215(4):423-430. DOI: 10.1016/j.ajog.2016.06.023.

6. Norman M, Piedvache A, Børch K, Huusom LD, Bonamy AKE, Howell EA, et al. Association of short antenatal corticosteroid administration-to-birth intervals with survival and morbidity among very preterm infants results from the EPICE group. JAMA Pediatr. 20171 July;171(7):678-686. DOI: 10.1001/jamapediatrics.2017.0602.

7. Cartwright RD, Crowther CA, Anderson PJ, Harding JE, Doyle LW, McKinlay CJD. Association of Fetal Growth Restriction With Neurocognitive Function After Repeated Antenatal Betamethasone Treatment vs. Placebo: Secondary Analysis of the ACTORDS Randomized Clinical Trial. JAMA Netw Open. 2019 Feb 1;2(2):e187636. DOI: 10.1001/jamanetworkopen.2018.7636.

8. Asztalos E V., Murphy KE, Willan AR, Matthews SG, Ohlsson A, Saigal S, et al. Multiple courses of antenatal corticosteroids for preterm Birth study outcomes in children at 5 years of age (MACS-5). JAMA Pediatr. 2013 Dec;167(12):1102-1110. DOI: 10.1001/jamapediatrics.2013.2764.

9. Besnard AE, Wirjosoekarto SAM, Broeze KA, Opmeer BC, Mol BWJ. Lecithin/sphingomyelin ratio and lamellar body count for fetal lung maturity: A meta-analysis. Eur J Obstet Gynecol Reprod Biol. 2013;169(2):177-183. DOI: 10.1016/j.ejogrb.2013.02.013.

10. Shanks AL, Grasch JL, Quinney SK, Haas DM. Controversies in antenatal corticosteroids. Semin Fetal Neonatal Med. 20191 June;24(3):182-188. DOI: 10.1016/j.siny.2019.05.002.

11. Jobe AH, Kemp MW, Kamath-Rayne B, Schmidt AF. Antenatal corticosteroids for low and middle-income countries. Semin Perinatol. 20191 August;43(5):241-246. DOI:10.1053/j.semperi.2019.03.012.

12. The American College of Obstetricians and Gynecologists. Antenatal Corticosteroid Therapy for Fetal Maturation. Obstet Gynecol [Internet]. 2017;140(3):102-109. DOI: 10.1542/ peds.2017-2082. Available from: https://www.acog.org/-/media/ Committee-Opinions/Committee-on-Obstetric-Practice/co713. pdf?dmc $=1 \&$ ts $=20200125 T 1631437144$

13. Watterberg KL, Ballard PL. Optimizing antenatal corticosteroid therapy for improving the outcome of preterm infants. Pediatr Res. 2019 Nov 1;86(5):556-557. DOI: 10.1038/s41390-019-0538-x. 
14. Crowther CA, McKinlay CJ, Middleton P, Harding JE. Repeat doses of prenatal corticosteroids for women at risk of preterm birth for improving neonatal health outcomes. Cochrane Database Syst Rev. 201115 June;6:CD003935. DOI: 10.1002/14651858. CD003935.pub3.

15. Hutchinson M, Hodgden JD. Clinical Question: In women with preterm labor, do repeated courses of prenatal corticosteroids improve neonatal outcomes compared to a single course? J Okla State Med Assoc [Internet]. 2018 Jan [cited 2020 Jan 3];111(1):498-499. ISBN: 0030-1876. Available from: http://www. ncbi.nlm.nih.gov/pubmed/30532343

16. Frey HA, Klebanoff, MA. The epidemiology, etiology, and costs of preterm birth. Semin Fetal Neonatal Med. 2016 April;21(2):68-73. DOI: 10.1016/j.siny.2015.12.011.

17. Kemp MW, Schmidt AF, Jobe AH. Optimizing antenatal corticosteroid therapy. Semin Fetal Neonatal Med. 20191 June;24(3):176- 